\title{
'Horizontal' Wells
}

\section{W. T. WELCHERT AND BARRY N. FREEMAN}

Highlight: Forty-five horizontal wells were constructed on the San Carlos Apache Indian Reservation during 1967-69. This paper describes site selection, drilling equipment, and the construction process and lists the advantages of the horizontal well system over more conventional systems.

Adequate water supplies, located for best utilization of range resources, are essential to good range management. A rancher doesn't need a large water yield in most areas. A single watering site can serve one to three sections of rangeland. In Arizona, the typical beef cattle stocking rate varies from four to ten animal units per section. At 12 to 15 gallons per animal-day, the maximum potential use per watering site is less than 500 gallons per day (gpd).

A yield of 0.25 gallons per minute ( $\mathrm{gpm}$ ) may serve a single watering site. A lesser flow may be utilized with the addition of tank storage designed to accumulate water to match the anticipated demand for the grazing season. Even spring sites that flow for only a few weeks in the year may prove useful with adequate storage.

A yield of 3 to 10 gallons per minute $(4,000$ to $14,000 \mathrm{gpd})$ may be extended to a dozen or more water sites through pipe distribution systems. One-inch pipe distribution systems of 10 miles or more are in use on a number of Arizona ranches.

Providing stock water at a suitable location and reasonable cost has always been a problem for the stockman. "Dirt tanks" (stock ponds) are relatively inexpensive, but reliability depends upon soil factors and rainfall. Runoff aprons and catchment basins are expensive, require some maintenance, and are dependent upon regular precipitation. Conventional wells are reliable but expensive, and associated pumping equipment may require considerable maintenance.

Properly developed springs approach the ideal range water supply specifications, but are often wasteful of water. Spring development is an ancient art. When a water seep or other evidence of a potential spring is located, it is either dug or blasted to expose the aquifer. The results are erratic and

The authors are extension agricultural engineer and extension range management specialist, University of Arizona, Tucson.

This contribution was approved for publication as Journal Paper No. 1979 by the Agricultural Extension Service, University of Arizona, Tucson.

The authors gratefully acknowledge the cooperation of the drilling contractors, Albert W. Smith of Crestline, California, and his son Errol Smith of Globe, Arizona, and of Gunter Prude, retired, head stockman for the San Carlos Apache Tribal Council.

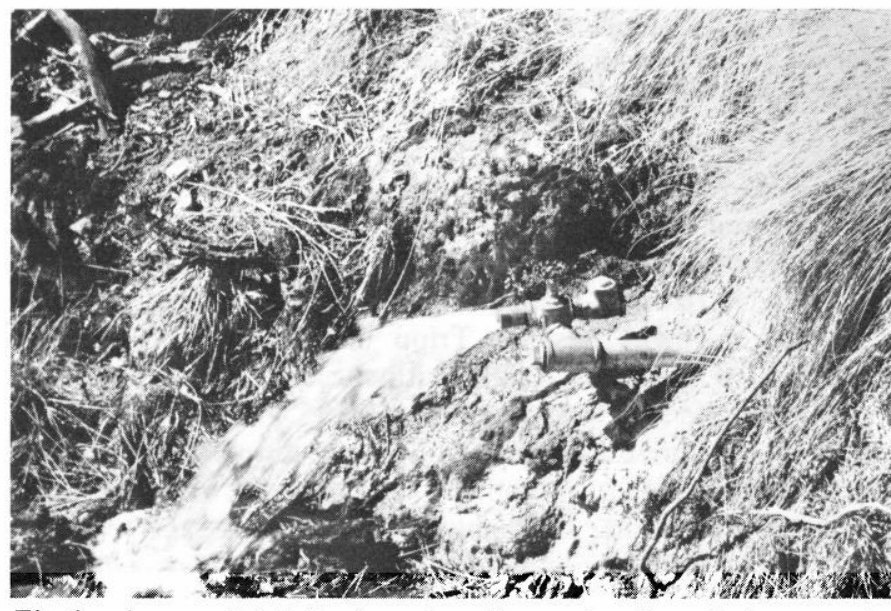

Fig. 1. A completed horizontal well on the San Carlos Apache Reservation test yields over $50 \mathrm{gpm}$.

include the risk of permanently destroying a natural barrier which may be serving as a dam for the underground reservoir. The flow, once established, is almost impossible to control and may result in rapid depletion of the stored water. The horizontal well virtually eliminates the disadvantages of conventional spring development techniques. Each of these methods has a place in providing range water supplies and will continue to play a role.

\section{Origin and Development of Horizontal Wells}

Horizontal wells are a recent addition to the range water development picture. They have a tremendous potential in areas having favorable geological formations. Fortunately, such areas include a substantial portion of the better rangeland in Arizona and the mountain states.

A horizontal well is simply a horizontally-cased well in a water-bearing formation (Fig. 1). A "horizontal" boring rig (Fig. 2) is used to drill a hole and install pipe into a mountain or hillside at a slight downward slope to tap impounded groundwater.

Although miners, road builders, plumbers, electrical contractors, and geologists have developed equipment and techniques for horizontal boring, little attention has been given to adapting these techniques to water supply development. The equipment used to construct horizontal wells is also used to construct horizontal drains for control of landslides in 


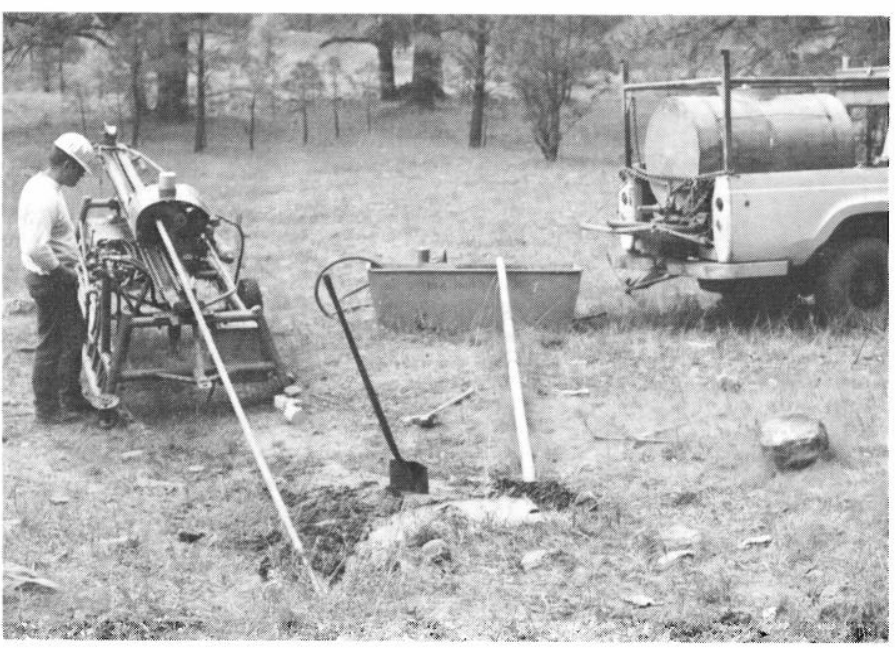

Fig. 2. Horizontal well drilling equipment should be as light and portable as practical for use in rough range country. Note that water is recirculated through a rotary wet-boring drill stem. The heart of the rig is a pipe chuck which turns at about 100 rpm and is powered by a $10 \mathrm{hp}$ gas engine.

California. Hellesoe (1941) reported that the first installation of horizontal drains was made on the Cuesta Grade in 1939. In 1948, Stanton (1948) reported on the Hydrauger Method of installing horizontal drains on 53 landslide areas of the California highway system. Tripp (1963) credited Eric A. Anderson of Petaluma, Calif., with successful horizontal well drilling in the early 1950's. Root (1955) reported on the progress of horizontal drill equipment development. These reports indicate that equipment development was stimulated by drillers competing for highway drainage contracts and that the practice of horizontal well drilling evolved as a natural extension of earlier experience in constructing horizontal drains. It is also probable that a number of early innovators from both arts have contributed to the evolution of the equipment and drilling techniques. To date, the most effective equipment has been designed, built, and rebuilt by the drilling contractors.

The driller-cooperator on the San Carlos Apache Reservation has demonstrated three different "generations" of equipment while developing about 50 producing wells during the period from 1967 to 1969 .

\section{Site Selection}

Potential sites are located by evidence of a water seep, presence of water-loving plants, or observation and analysis of geologic formations. Generally, a site will show geological evidence of either a natural dike or a "contact" type of spring.

The dike formation (Fig. 3) is a geologically tilted impervious formation, such as rock, which forms a natural barrier to an aquifer; in essence, a natural dam for an underground water storage reservoir. Water may not be visible, or it may seep through cracks in the dike or over the top of the barrier. The objective in horizontal well development of a dike formation is to drill through the barrier somewhere below the seep and tap the storage water.

The contact type (Fig. 4), consisting of a perched water table above an impervious material, is more difficult to recognize. Water seeps out at a point near the outcropping impervious layer. The line of seepage can frequently be located by observing the presence of water-loving plants. Drilling below the seepage will often fail to increase the yield because the entry may be into the impervious layer.

\section{Drilling Equipment and Process}

A rotary method of drilling is used with recirculating water to remove the drill cuttings. Standard lengths of $1 \frac{114}{4}$-inch nominal diameter extra strength steel pipe are used as the drill stem. The drill bit is a standard pipe coupling with tungsten-carbide blanks welded into notches in the leading edge (Fig. 5) which bores a hole with a diameter about $1 / 4$-inch larger than the coupling. The drill bit must be small enough to clear the inside of a standard two-inch casing. The drill stem is clamped in a chuck and rotated at about $100 \mathrm{rpm}$ as the chuck and stem are moved forward on a carriage. The equipment must be rugged and, equally important, light and portable for transport to sites in rugged terrain.

Drilling is started at a likely site with a minimum downward slope of $1 / 2$-inch per foot. Water, pumped through the rotating drill stem, washes the cuttings back through the annular clearance between the hole and the stem. A portable gasoline engine-driven pump with at least 3 gallons per minute capacity at 120 pounds per square inch provides water return velocity of 1.0 to 1.5 feet per second necessary to cool the bit and to remove the cuttings. A continuous flow of return water is essential to prevent binding of the drill stem in the hole. Return flow is directed to a holding pond for settling and reuse. A readily available source of 100 to 300 gallons of water per day is necessary.

The drilling rate usually varies from 3 to 9 inches per minute through heavy clay, decomposed granite, or soft rock. In extremely hard rock, the rate may be less than 1 inch per minute. When this occurs, the carbide bit is replaced with a commercial diamond drill bit.

When the drilling produces evidence of a water supply, the exposed lengths of drill stem are removed, leaving just enough stem to serve as a guide for a two-inch casing. This stem is then equipped with a drill stem plug and pickup guide (Fig. 6) which serves to keep recirculating water out of the drill stem during placement of the casing. The tapered end of the plug also serves as a guide for recoupling to the drill stem for removal after the casing is set.

\section{Cementing in the Casing}

The two-inch casing, equipped with a carbide-tipped coupling, is used to ream the hole around the drill stem guide until contact is made with the impervious layer. Drilling is stopped when the exposed end of the casing provides a convenient location for an outlet tee connection. A section of pipe and a standard coupling is attached to the pickup guide, and the $1 \frac{1}{4}$-inch drill stem is removed from the casing.

Another hole is then drilled immediately alongside the casing, penetrating several feet to form a control path for

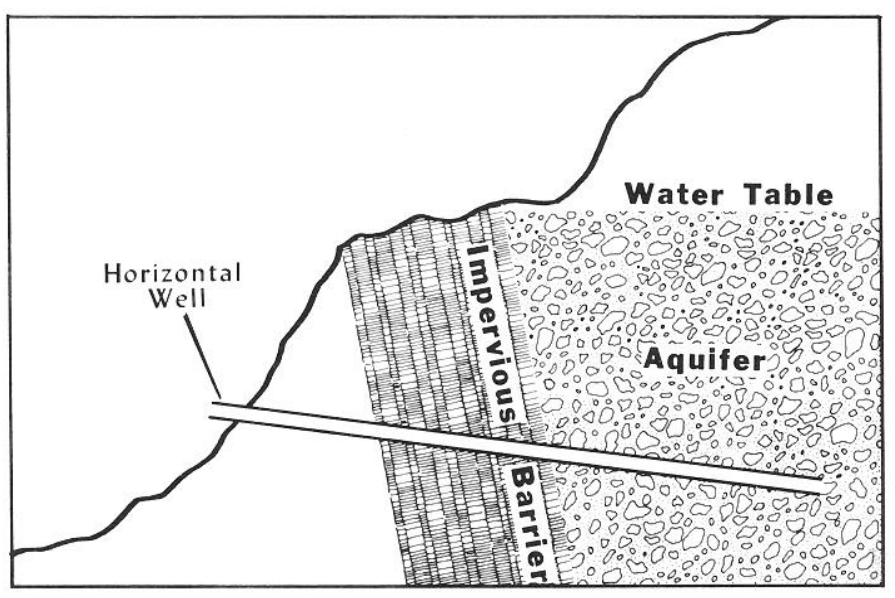

Fig. 3. Dike spring formation. 


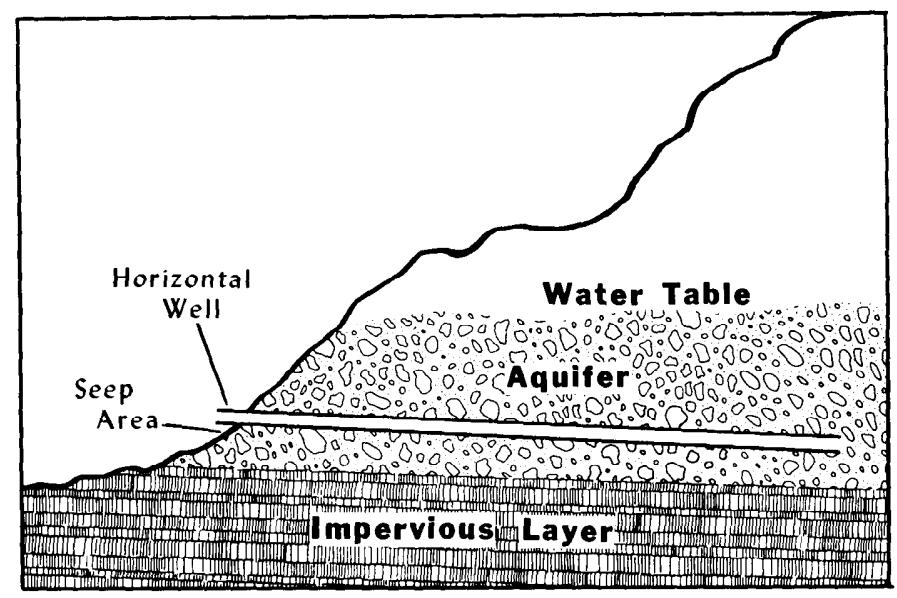

Fig. 4. Contact type of spring formation.

cementing the casing in place. A cement slurry pressure tank, containing about two sacks of plastic cement slurry mixed to a consistency of heavy cream is then connected, so that water pressure from the pump forces the slurry into the annular void and soil surrounding the casing. The drill stem is sealed at the ground by packing paper around the stem. Pumping is stopped when the cement begins to show in the casing return flow. The drill stem is then removed and the slurry is allowed to set, usually overnight.

The next morning, the drill stem is reinserted inside the casing and drilling continued until a satisfactory yield is established or until the practical limit of the drilling has been reached. The drill stem is then replaced with 11/4-inch perforated pipe, usually the full length of the hole or at least through the principal water-bearing strata, to keep the hole open.

\section{Plumbing}

The plumbing for the system is simple, consisting of a gate valve, vacuum relief valve, and fittings, all attached to a tee at the end of the casing. Normally, a bibb faucet is added to provide drinking water for both the ranchers and hunters. If the relief valve is subject to fouling from dirt or debris, a riser is included. With the well at a downward slope into the aquifer, the tee and air relief valve are at the high point in the system and the vacuum relief valve prevents the formation of a vacuum in the casing when flow rate exceeds water yield from the formation. If the vacuum were permitted to exist, fine grained materials would be sucked from the water bearing strata into the system.

The elevation of the water in the aquifer above the outlet provides a head of water, making this a completely automatic water system. From the tee, the necessary distribution pipe is connected to the float controlled watering sites.

\section{Drilling Results}

A serviceable water supply was obtained at 45 of the 53 locations where development was attempted on the San Carlos Apache Indian Reservation. It should be pointed out that success is a measure of both the driller's skill in site sclection and the geological character of the area. Success was defined as a yield of 0.25 or more gallons per minute. Flow measurements were made after the plumbing of the well was completed, at which time the well normally had been running for a day or more. Yield estimates varied from 0.25 to 60 gallons per minute, and most were in the 3 to $10 \mathrm{gpm}$ range.

Because every area has unique problems, drilling success and cost of development will vary considerably. Drilling distance at San Carlos varied from 41 to 270 feet and averaged 123 feet per producing well. Neither the shortest hole at 41 feet nor the longest at 270 feet were the least or most expensive site. The well record at the Blue Spring site shows a total development time of only 12 hours for a 101-foot hole, while at Johnny Spring, 52.5 hours were required to complete a 90 -foot well. Development time averaged 32.3 hours per producing well.

The well construction costs averaged $\$ 500$ per producing well, including $\$ 50$ for plumbing supplies. This cost includes the dry holes and time spent on site preparation and road building, but does not include pipe distribution and water tank systems.

\section{Advantages}

The horizontal well system has a number of advantages over other range water supply systems:

1) When compared with conventional springs, water loss is minimized since the flow can be controlled by float valve or completely shut off when not required.

2) The system provides a sanitary water supply. Normally, spring water supplies are of good quality and purity as they emerge from the ground. However, contamination in a spring area is common and difficult to control. With the horizontal well, the possibility of contamination at this point is virtually eliminated.

3) The cost of the horizontal well will normally be substantially less than other water supply systems. The construction cost is moderate; maintenance cost is low and the operational cost is insignificant.

4) The chances of developing a successful water supply with a horizontal well are greatly improved over conventional spring development methods. Several of the better yielding wells in the San Carlos area were developed where there was no evidence of a spring or water seep.

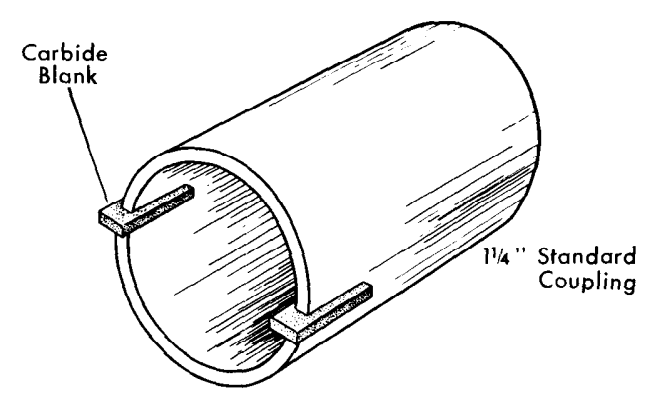

Fig. 5. Drill bit.

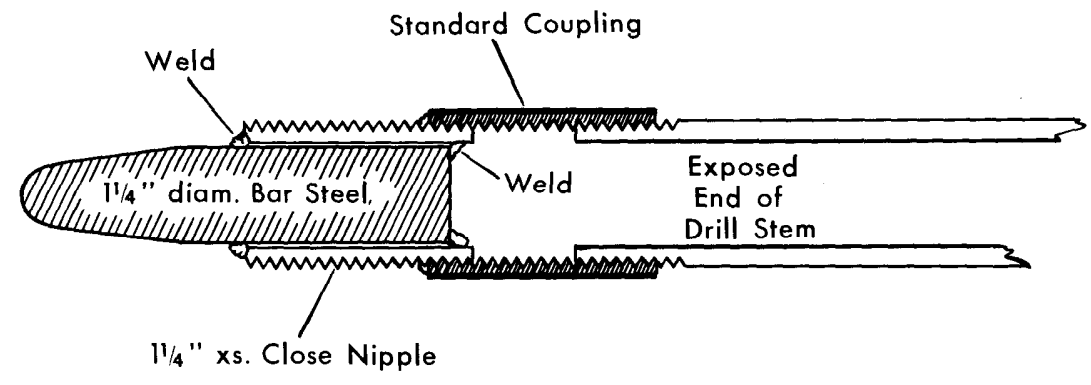

Fig. 6. Drill stem plug and pickup guide. 
Arizona ranchers are enthusiastic about the potential application of horizontal well drilling in remote and rough country.

\section{Literature Cited}

Hellesoe, G. F. 1941. Los Gatos-Santa Cruz highway slipout. Calif. High- ways and Public Works. 19(12):3-7.

Root, A. W. 1955. Horizontal drill, Calif. Highways and Public Works. 34(3):26-29.

Stanton, T. E. 1948. Hydrauger method. Calif. Highways and Public Works. 27(1):6-10).

Tripp, Vollie. 1963. Not how deep but how long says this driller. Water Well J. 17(5):21, 36-38. 